\section{Uniformity of Sand Deposition on Cranberry Farms and Implications for Swamp Dodder Control}

\author{
Laura K. Hunsberger ${ }^{1}$, Carolyn J. DeMoranville ${ }^{2}$, \\ Wesley R. Autio ${ }^{3}$, and Hilary A. Sandler ${ }^{2}$
}

AdDITIONAL INDEX wORDs. Cuscuta gronovii, Vaccinium macrocarpon, IPM, cultural controls, parasitic weeds

\begin{abstract}
SUMMARY. Uniformity of sand deposition on cranberry (Vaccinium macrocarpon) farms was examined to evaluate the potential use of two sanding methods to suppress swamp dodder (Cuscuta gronovii) seedling emergence by seed burial. During a 2-year study, 24 farms were evaluated with sand applied by either water barge or directly on ice. To measure the depth of sand deposited on the surface, soil cores were taken every $5 \mathrm{~m}$ in a grid pattern on a randomly selected portion of a commercial Massachusetts cranberry farm. Both application methods delivered nonuniform depositions of sand with the majority of the samples measuring less than the target depth. Surface diagrams depicting sand depths indicated no particular patterns of error or deposition that could be advantageously adjusted by the grower at the time of application. Mean actual : target depth ratios were $63 \%$ and $66 \%$ for barge and ice sanding, respectively (100\% indicating actual equaled target). In the best scenario (two farms), $47 \%$ of the sanded area received less than the target amount; 11 farms had at least $90 \%$ of actual sand depths below the target depth. For farmers targeting 25- $\mathrm{mm}$ sand depths (depth expected to suppress dodder germination), the mean actual : target depth ratio was $58 \%$, indicating half of the actual sand depths measured less than $15 \mathrm{~mm}$. Compaction of the sand layer due to the elapsed time period ( 6 weeks or more) between sand application and measurement may have contributed to the large number of samples that were lower than the target depth. Even so, the irregularity of deposition patterns and the large proportion of sand depths that were less than $25 \mathrm{~mm}$ indicated adequate suppression of dodder seedling emergence would be unlikely with either sanding method.
\end{abstract}

$S$ wamp dodder can cause severe infestations in commercial cranberry farms in Massachusetts and Wisconsin production regions (Bewick et al., 1989; Devlin and Deubert, 1980). Dodder is an obligate parasite that invades the vascular tissue of host plants to obtain water and carbohydrates. Heavy infestations can result in

We acknowledge the excellent technical assistance of Melissa Cannon and Liz Little. We also thank L. Briggs, Decas Cranberry Company, Edgewood Cranberry Trust, and Hiller Cranberry Company for use of their properties. We acknowledge the constructive comments of the anonymous reviewers. The research was funded in part by Ocean Spray Cranberries, Inc., Lakeville-Middleboro, Mass.; and Cape Cod Cranberry Growers' Association, East Wareham, Mass.

${ }^{1}$ Maryland Cooperative Extension, Worcester County, P.O. 219, Snow Hill, MD 21863. This paper is a portion of a thesis submitted by the senior author in fulfilling master's degree requirements. To whom reprint requests should be addressed; e-mail address: lhuns@umd.edu

${ }^{2}$ University of Massachusetts-Amherst Cranberry Station, P.O. Box 569, East Wareham, MA 02538.

${ }^{3}$ University of Massachusetts, Department of Plant, Soil, and Insect Sciences, Bowditch Hall, Amherst, MA 01002. yield losses of $80 \%$ to $100 \%$ in cranberry (Devlin and Deubert, 1980).

The periodic application of a thin layer $(10-50 \mathrm{~mm})$ of sand over cranberry vines during the dormant season (sanding) is a cultural practice used in cranberry production primarily to stimulate rooting and production of vertical stems (uprights) (DeMoranville, 1997). Sanding also is used to encourage organic matter decomposition (Cross and Demoranville, 1978) and has pest management benefits, including burial of cranberry girdler (Chrysotenchia topiaria) pupae and suppression of fruit rot (Physalospora vaccinii) inoculum (Tomlinson, 1937). The application of at least $25 \mathrm{~mm}$ of sand on top of dodder seeds was needed to reduce seedling emergence in greenhouse tests (Sandler et al., 1997). Sand can be applied directly onto dry vines by ground rigs that ride on the vines (dry sanding) or on rails (rail sanding), applied during the winter on top of frozen flood waters (ice sanding), or delivered via a floating barge in shallow flood waters (barge sanding) during the spring or fall (DeMoranville et al., 1996).

Although yield is typically reduced in the year of application, sanding can have variable effects on subsequent yield. Application method and depth of sanding are important factors. The application of $13 \mathrm{~mm}$ of sand directly to dry vines increased yield in the year of sanding on a mature cranberry bed, with no effect the following year (Strik and Poole, 1995); however, as sand deposition increased to $25 \mathrm{~mm}$, yield decreased. Yield was reduced in cultivars Early Black and Stevens from 25 $\mathrm{mm}$ of sand applied by barge sanding (Davenport and Schiffhauer, 2000). Although fruit size was increased in the third year after sanding, overall yield was not increased.

A dodder management program currently includes such control measures as preemergence herbicides, control of early-season hosts, manual removal, and applications of postemergence products (Hunsberger et al., 2006; Morrison et al., 2005; Sandler, 2005). Since burial of dodder seeds with at least $25 \mathrm{~mm}$ of uniformly applied sand suppressed seedling emergence in greenhouse studies, consideration was given to include sand application as a component in an integrated management program for dodder. Before inclusion as part of standard recommendations, an assessment of the uniformity of sand application to cranberry farms was needed. The objectives of this study were to evaluate the uniformity of sand deposition under commercial conditions and to determine if sand application could be a useful component in an integrated plan for dodder management.

\begin{tabular}{llll}
\hline $\begin{array}{l}\text { Units } \\
\begin{array}{l}\text { To convert U.S. to SI, } \\
\text { multiply by }\end{array}\end{array}$ & U.S. unit & SI unit & $\begin{array}{l}\text { To convert SI to U.S., } \\
\text { multiply by }\end{array}$ \\
\hline 102.7902 & acre-inch(es) & $\mathrm{m}^{3}$ & 0.0097 \\
0.3048 & $\mathrm{ft}$ & $\mathrm{m}$ & 3.2808 \\
2.54 & inch(es) & $\mathrm{cm}$ & 0.3937 \\
25.4 & inch(es) & $\mathrm{mm}$ & 0.0394 \\
0.7646 & yard & $\mathrm{m}^{3}$ & 1.3080
\end{tabular}




\section{Materials and methods}

In Spring 1996 and 1997, about 12 Massachusetts cranberry growers were contacted, initially by mail and subsequently by telephone, explaining the purpose of the research and criteria desired. Selection of farms was limited to sites where sanding had previously occurred, where a target depth was known, and where the grower was willing to permit access to the property for sampling. Using this process, 24 commercial cranberry farms located in southeastern Massachusetts were identified for evaluation (Table 1). Fifteen farms were sanded in water using barge equipment, and nine farms used equipment designed to apply sand on top of a thick $(12-15 \mathrm{~cm})$ ice layer. Overall, seven different sand depths were targeted, with five and six different sand depths targeted for barge and ice sanding, respectively (Table 1).

During the application process, growers periodically verify deposition of the target depth by pushing a physical measuring device into the sand layer (P. Beaton and C. Severance, personal communication). When sand is deposited on top of ice, multiple readings are taken throughout the day to verify that the hopper is delivering the expected (target) amount. The hopper opening, gear speed, etc., is modified until the desired amount is delivered. Calibration with barge sanding may be achieved by depositing sand into the water onto a specific area of ground (or onto a metal sheet or other layer), releasing the water, and taking a measurement with a metered stick. The hopper opening can be adjusted repeatedly until the expected amount is delivered. Measurement of sand deposition by barge is best performed once the water is removed. Deposition amounts can also be verified by knowing the volume of sand per hopper and determining the distance traveled.
Typically, 1 acre-inch requires 134 yard ${ }^{3}$ of sand (DeMoranville, 1997).

Recommendations for cranberry production include the use of screened sand (to remove large stones and gravel) that contains $70 \%$ of particles in the range of $0.5-2 \mathrm{~mm}$ diameter (DeMoranville et al., 1996). The use of washed sand (to remove silt and clay particles) is also recommended, but depending on the drainage characteristics of a particular farm, the presence of fine particles may actually be more desirable than not. Growers may excavate deposits on their own properties or purchase sand from commercial operations. Characterization of the sand applied to a particular farm is performed by the individual grower and may include any combination of past experience, visual and tactile inspection, jar test analysis, and (more recently, as growers increasingly purchase sand from external sources), certified laboratory analysis. Growers

Table 1. Comparison of sand deposition methods and description of frequency distributions for 24 southeastern Massachusetts commercial cranberry farms at which target depths were obtained from growers and actual sanding depths were measured during 1996-97.

\begin{tabular}{|c|c|c|c|c|c|c|c|c|c|c|}
\hline Farm & $\begin{array}{l}\text { Sanding } \\
\text { method }^{\mathrm{z}}\end{array}$ & Cultivar & $\begin{array}{l}\text { Target } \\
\text { depth } \\
(\mathrm{mm})^{y}\end{array}$ & $\begin{array}{l}\text { Mean } \\
\text { sand } \\
\text { depth } \\
(\mathrm{mm})\end{array}$ & $\begin{array}{c}\text { Area } \\
\text { receiving } \\
\text { less than } \\
\text { target } \\
\text { depth }(\%)\end{array}$ & $\begin{array}{c}\text { Samples } \\
\text { within } \pm 5 \% \\
\text { target } \\
\text { depth }(\%) \\
\end{array}$ & $\begin{array}{c}\text { Mean } \\
\text { actual: } \\
\text { target } \\
\text { ratio }^{x}\end{array}$ & $\begin{array}{c}\text { Normal } \\
\text { distribution } \\
(\mathrm{P})^{\mathrm{w}}\end{array}$ & $\begin{array}{l}\text { Skewness } \\
\left(\mathrm{g}_{1}\right)^{\mathrm{v}}\end{array}$ & $\begin{array}{l}\text { Kurtosis } \\
\left(\mathrm{g}_{2}\right)^{\mathrm{u}}\end{array}$ \\
\hline 1 & Barge & Early Black & 16 & 18.3 & 47 & 8 & 114 & 0.022 & 0.66 & 0.13 \\
\hline 2 & Barge & Early Black & 20 & 7.2 & 97 & 2 & 36 & $<0.001$ & 1.85 & 5.05 \\
\hline 3 & Barge & Early Black & 25 & 7.2 & 95 & 3 & 29 & $<0.001$ & 1.60 & 4.10 \\
\hline 6 & Barge & Early Black & 25 & 12.3 & 85 & 4 & 49 & $<0.001$ & 1.02 & 0.54 \\
\hline 7 & Barge & Early Black & 25 & 25.6 & 51 & 11 & 102 & 0.005 & 0.78 & 1.56 \\
\hline 8 & Barge & Early Black & 25 & 6.9 & 98 & 2 & 28 & 0.001 & 0.58 & 0.18 \\
\hline 9 & Barge & Early Black & 38 & 18.1 & 96 & 2 & 48 & 0.256 & 0.30 & 0.09 \\
\hline 10 & Barge & Howes & 20 & 21.3 & 56 & 18 & 106 & $<0.001$ & 1.72 & 2.72 \\
\hline 15 & Barge & Howes & 38 & 25.0 & 84 & 8 & 66 & 0.549 & 0.16 & 0.55 \\
\hline 16 & Ice & Early Black & 13 & 13.6 & 47 & 21 & 104 & 0.026 & 0.44 & 0.24 \\
\hline 17 & Ice & Early Black & 13 & 7.5 & 89 & 5 & 58 & $<0.001$ & 1.39 & 2.99 \\
\hline 18 & Ice & Early Black & 13 & 12.1 & 57 & 15 & 93 & 0.005 & 0.61 & 0.72 \\
\hline 19 & Ice & Early Black & 16 & 15.0 & 63 & 33 & 94 & $<0.001$ & 1.34 & 2.42 \\
\hline 20 & Ice & Early Black & 20 & 8.6 & 98 & 0 & 43 & $<0.001$ & 0.90 & 0.90 \\
\hline 21 & Ice & Early Black & 25 & 13.9 & 92 & 2 & 55 & $<0.001$ & 0.93 & 0.64 \\
\hline 22 & Ice & Early Black & 32 & 12.0 & 100 & 0 & 38 & 0.011 & -0.42 & -0.06 \\
\hline 23 & Ice & Howes & 22 & 11.9 & 95 & 0 & 54 & 0.002 & 0.87 & 1.88 \\
\hline 24 & Ice & Howes & 22 & 12.2 & 95 & 2 & 56 & 0.003 & 0.89 & 0.83 \\
\hline
\end{tabular}

${ }^{2}$ Barge $=$ sand delivered in a shallow flood; ice : sand delivered on top of frozen flood waters.

$\mathrm{y} 1 \mathrm{~mm}=0.0394$ inch

Values of 100 indicate actual equaled target; values below or above 100 indicate actual sand measurements were less than or greater than target depth, respectively.

wProbability of describing a normal distribution $(P>0.05)$ according to Shapiro-Wilk statistic.

"Negative $\mathrm{g}_{1}$ indicates tail of the curve is drawn out to the left; positive $\mathrm{g}_{1}$ indicates tail of the curve is drawn out to the right.

"Negative $\mathrm{g}_{2}$ indicates peak is lower than expected for the normal distribution; positive $\mathrm{g}_{2}$ indicates peak is higher than expected for the normal distribution. 
in this study used unwashed screened sand that was evaluated and deemed to be suitable for commercial application through the use of the first two aforementioned methods.

Sand depth measurements were made mid-April through early May, a time frame in-between the period after the sanding season (typically November through February) and the removal of the winter flood (usually late February to mid-March), but prior to the active growth period of the vines. Depending on the size of sanded area, up to five 50 - $\mathrm{m}$ transects were established across the sanded area. Sand depths were measured at 5-m intervals inserting a 20-mm-diameter metal soil sampling tube that had a length of $31 \mathrm{~cm}$ into the soil. The tube had an open portion in the cylinder at the lower end that permitted direct measurement of the sand depth with a ruler upon extraction of the core. One soil core was taken every $5 \mathrm{~m}$ along each transect. Depending upon available size of sanded area, 30-70 measurements were made per farm. Target depth was obtained from grower-provided information.

The format of this study precluded the use of traditional experimental design and subsequently, the use of analysis of variance. The authors acknowledge the limitation of the data set but submit that since many farms were sampled, generalized observations can be made, and descriptive statistics can be utilized. Readers should be aware that statements about method or target depth differences are not statistically substantiated but rather based on general observational trends in the data.

The mean sand depth, Shapiro-Wilk statistic (test for normal distribution), skewness $\left(\mathrm{g}_{1}\right)$, and kurtosis [peakedness $\left(\mathrm{g}_{2}\right)$ ] were determined for farm unit, target sand depth, and method of application. To allow comparisons of farms that had similar target depths or application methods, data were expressed as actual : target depth ratios. Values of 100 would indicate measured depth equaled the target depth. Values below or above 100 indicated measured depths were less than or greater than the target depth, respectively. These ratios were used to generate surface graphs that depict the patterns of sand deposition across the sampled area.

\section{Results and discussion}

The expected deposition of a uniform layer of sand across the production area was not achieved on the farms evaluated in this study. Regardless of application method, most locations of the production area received either greater or less than the target amount. In general, the production area received less sand than the target depth. More than half of the area for 22 of the 24 farms measured less than the target depth (Table 1). Eighteen farms had $10 \%$ or less of the samples within $5 \%$ of the target depth. The most accurate mean deposition was on Farm 19 with $33 \%$ of the samples within $5 \%$ of the target depth. Only one-quarter of the farms had actual: target depth ratios between $93 \%$ and $114 \%$; a value of 100 indicates that mean sand depth across the production area equaled the target depth (Table 1).

Combining data from all farms, the mean ratio of actual to target depth was $63 \%$ for barge sanding and $66 \%$ for ice sanding, respectively. Sand deposition on ice was more accurate (i.e., actual : target ratio closer to 100) when growers were targeting lower depths; deposition was less accurate at higher target depths (Table 2). The highest percentage of samples within $5 \%$ of the target depth was seen at Farm 19, which was ice sanded with a target depth of $16 \mathrm{~mm}$. Barge sanding was inaccurate at most sand depths. The most accurate deposition of sand by barge occurred at Farm 10, where the target depth of $20 \mathrm{~mm}$ was exceeded only slightly (Table 1). Evaluation of

Table 2. Comparison of sanding methods conducted 1996-97 on 24 commercial cranberry farms in southeastern Massachusetts with respect to grower-identified target depth, mean sand depth, ratio of actual and target depths, and descriptions of frequency distributions.

\begin{tabular}{|c|c|c|c|c|c|c|c|c|}
\hline $\begin{array}{l}\text { Target } \\
\text { depth } \\
(\mathrm{mm})^{\mathrm{z}}\end{array}$ & Methody & $\mathbf{N}$ & $\begin{array}{c}\text { Farms } \\
\text { (no.) }\end{array}$ & $\begin{array}{c}\text { Mean } \\
\text { sand depth } \\
(\mathrm{mm})\end{array}$ & $\begin{array}{c}\text { Mean } \\
\text { actual : target } \\
\text { ratio }^{\mathrm{x}}\end{array}$ & $\begin{array}{c}\text { Normal } \\
\text { distribution } \\
(\mathrm{P})^{\mathrm{w}}\end{array}$ & $\begin{array}{c}\text { Skewness } \\
\left(\mathrm{g}_{1}\right)^{\mathrm{v}}\end{array}$ & $\begin{array}{c}\text { Kurtosis } \\
\left(\mathrm{g}_{2}\right)^{\mathrm{u}}\end{array}$ \\
\hline 13 & ice & 190 & 3 & 11.0 & 85 & $<0.001$ & 0.78 & 0.63 \\
\hline 16 & barge & 65 & 1 & 18.3 & 114 & 0.021 & 0.66 & 0.14 \\
\hline 16 & ice & 55 & 1 & 15.0 & 94 & $<0.001$ & 1.34 & 2.40 \\
\hline 16 & ice/barge & 120 & 2 & 16.8 & 105 & $<0.001$ & 1.09 & 1.51 \\
\hline 20 & ice/barge & 185 & 3 & 11.5 & 58 & $<0.001$ & 3.13 & 12.32 \\
\hline 22 & ice & 131 & 2 & 12.1 & 55 & $<0.001$ & 0.86 & 1.34 \\
\hline 25 & barge & 520 & 9 & 14.5 & 58 & $<0.001$ & 1.09 & 1.91 \\
\hline 25 & ice & 65 & 1 & 13.9 & 55 & $<0.001$ & 0.93 & 0.64 \\
\hline 25 & ice/barge & 585 & 10 & 14.4 & 58 & $<0.001$ & 1.11 & 2.05 \\
\hline 32 & barge & 66 & 1 & 17.0 & 53 & 0.054 & 0.54 & 1.65 \\
\hline
\end{tabular}

${ }^{\mathrm{z}} 1 \mathrm{~mm}=0.0394$ inch

${ }^{\mathrm{B}}$ Barge $=$ sand delivered in a shallow flood; ice : sand delivered on top of frozen flood waters;

ice/barge = values calculated for both methods combined at each target depth.

'Values of 100 indicate actual equaled target; values below or above 100 indicate actual

sand measurements were less or greater than target amount, respectively.

"Probability of describing a normal distribution $(P>0.05)$ according to Shapiro-Wilk statistic.

"Negative $g_{1}$ indicates tail of the curve is drawn out to the left; positive $g_{1}$ indicates tail of the curve is drawn out to the right.

"Negative $\mathrm{g}_{2}$ indicates peak is lower than expected for the normal distribution; positive $\mathrm{g}_{2}$ indicates peak is higher than expected for the normal distribution. 


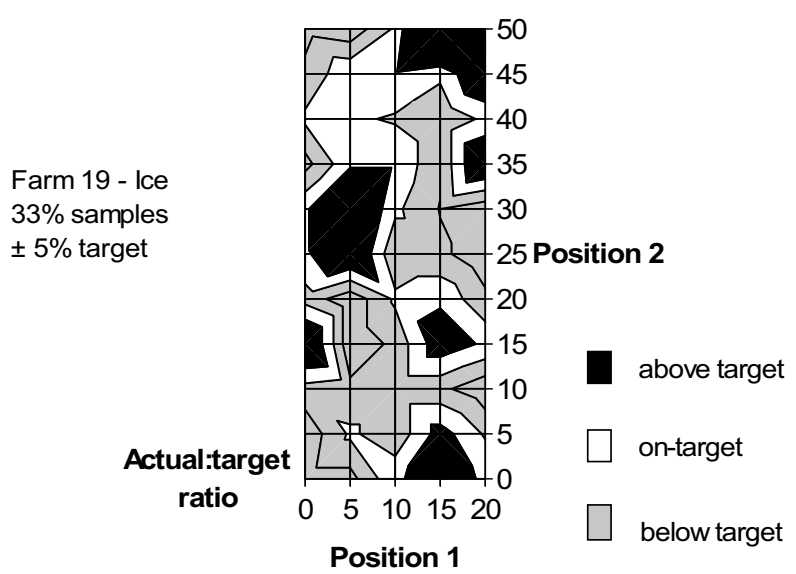

Fig. 1. Surface diagram of sand depths deposited by ice sanding (sand applied on frozen flood waters) on a commercial Massachusetts cranberry farm that had the highest percentage of samples within 5\% target depth (Farm \#19, see Table 1).

deposition of the target depth, irrespective of method or by combination of methods, indicated that the highest actual: target depth ratios were achieved at $16 \mathrm{~mm}$ (Table 2).

Although deposition on Farms 10 and 19 was relatively accurate in terms of actual: target ratios, the schematics of the actual deposition indicated arbitrary (nonuniform) patterns. For Farm 19, the pattern does not indicate that uniformity could be easily improved with changes in application technique (Fig. 1). However, the barge sanding on Farm 10 deposited excess sand at either end of the farm and below-target sand amounts in the center (Fig. 2). Based on this site, uniformity of barge sanding might be improved by releasing less sand at either end of the production area. However, surface diagrams of sites with the highest actual : target ratio for barge and ice sanding indicated no particular patterns of error or deposition (Fig. 3), even using the wide range of $\pm 25 \%$ of the target depth. If improvements are to be made in the uniformity of sand deposition to the production surface, more studies are needed to fully evaluate the range of deposition patterns delivered by these methods.

Combining all farms that used similar sanding methods, the frequency distributions of actual : target ratios for ice sanding, barge sanding, and growers targeting $25 \mathrm{~mm}$ had patterns of sand deposition that were positively skewed (i.e., the tail of the curve drawn out to the right) with peaks in the 40-60 actual : target ratio class (Fig. 4). This was not surprising since most of the farms had skewed and peaked distributions when analyzed individually (Table 1). Barge sanding had a higher percentage of samples with zero sand than ice sanding as well as several samples that were more than three times in excess of the target depth. Of the 10 farms that were targeting $25 \mathrm{~mm}$ of sand, $84 \%$ of the samples measured less than $25 \mathrm{~mm}$ (Fig. 4).

Deposition of sand to the production surface is influenced by several factors, including the skill of the operator as well as prevailing and subsequent

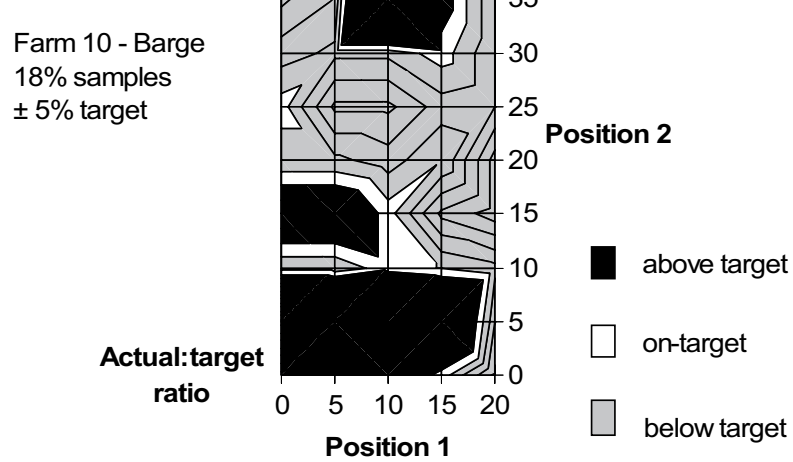

Fig. 2. Surface diagrams of sand depths deposited by barge sanding (sand applied in shallow flood waters) on a commercial Massachusetts cranberry farm that had the highest percentage of samples within $5 \%$ target depth (Farm \#10, see Table 1).
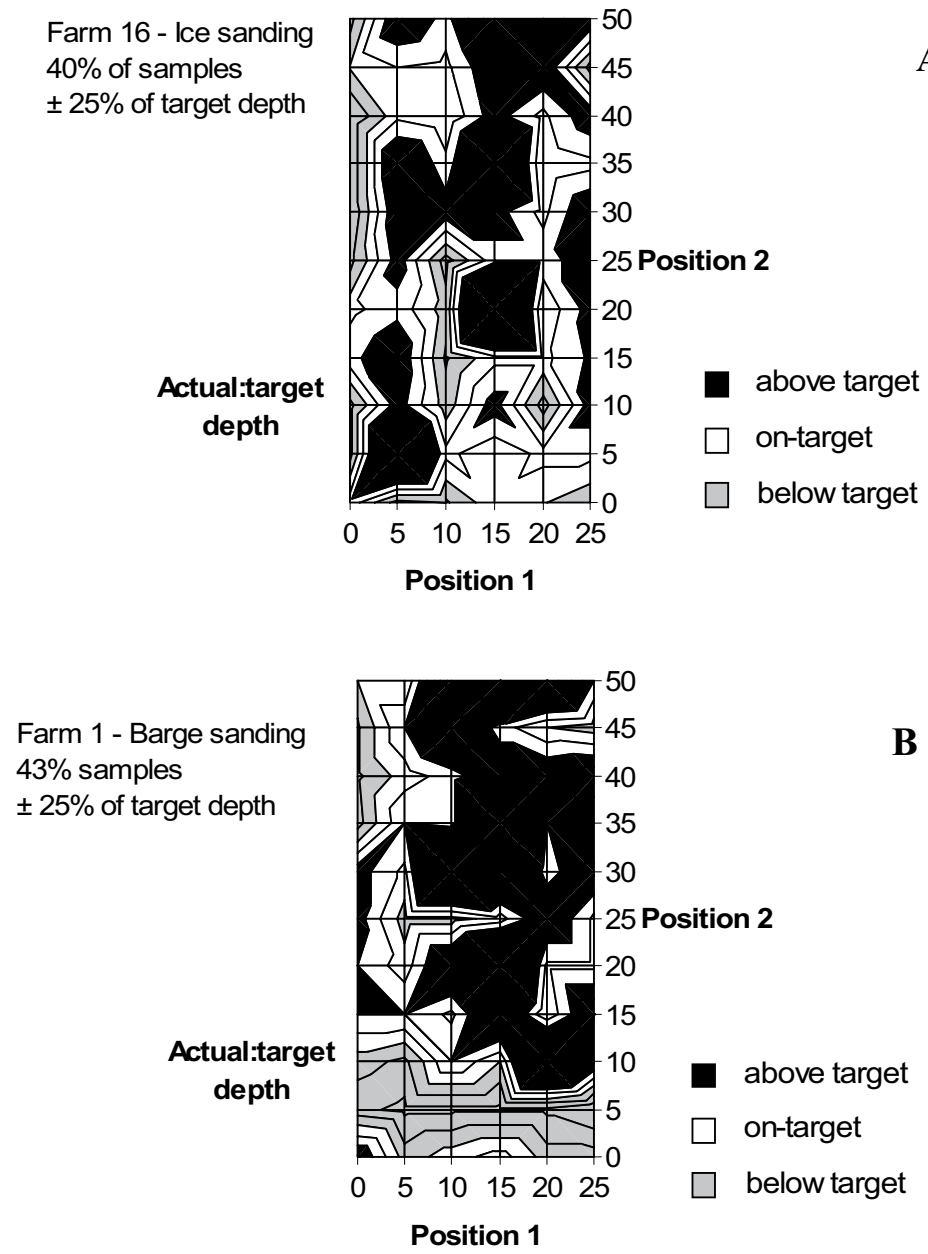

Fig. 3. Surface diagram of sand depths deposited by (A) ice sanding (sand deposited on frozen flood waters) or (B) barge sanding (sand applied in shallow flood waters) on commercial Massachusetts cranberry farms that had the lowest percentage of samples below the target depth (Farms \#16 and \#1, respectively; see Table 1). Figures indicate patterns of sand deposition for samples within $25 \%$ of target depth. 


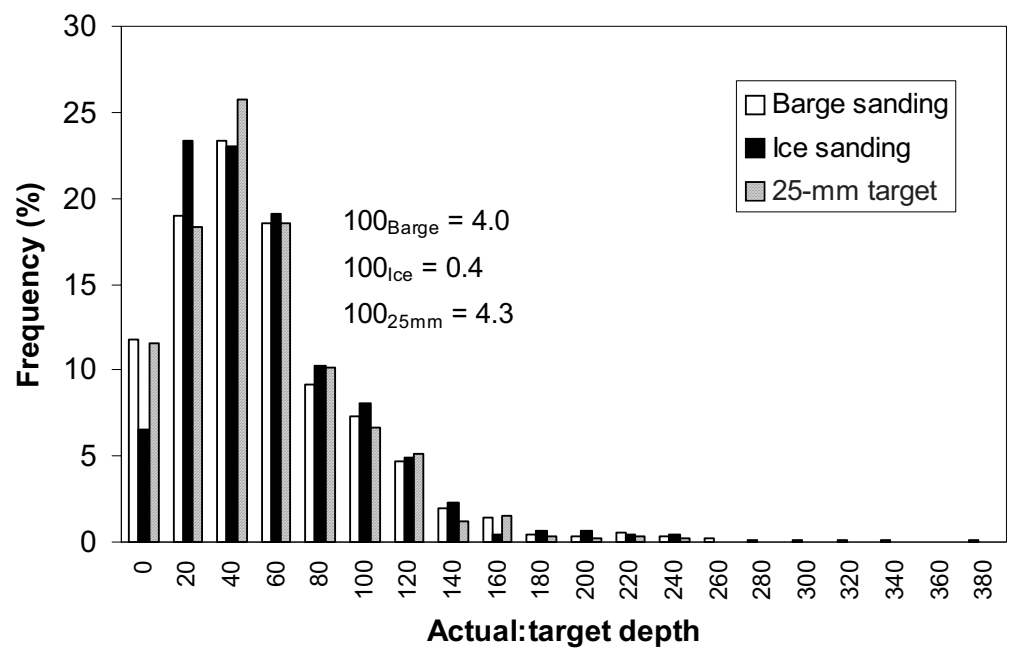

Fig. 4. Frequency distribution of actual: target depth ratios for farms using barge sanding (sand deposited in shallow flood waters; $N=15$ ), ice sanding (sand deposited on frozen flood waters; $\mathrm{N}=9$ ), and 10 farms targeting $25-\mathrm{mm}$ sand depth (depth for suppression of dodder seedling emergence). Values of 100 indicate actual depths equaled the target depth; values below or above 100 indicate actual depths were less than or greater than the target depth, respectively. Subscripted numbers indicate the percentage of values exactly equal to 100. Bars towards the far right of the $\mathrm{x}$-axis are from barge sanding only $(1 \mathrm{~mm}=0.0394$ inch $)$.

weather conditions (P. Beaton and $\mathrm{K}$. Mann, personal communication). Sand applications are typically performed during the winter months when cold temperatures can cause sand particles to adhere to each other and hinder proper discharge from the hopper. Experienced growers can minimize off-target drift of dry sand by carefully manipulating the water levels in the production area and moistening the newly deposited sand. Even when a uniform layer had been deposited and moistened, uneven melting of the ice could cause nonuniform deposition of sand to the vines. Deposition of sand by barge equipment can be influenced by current wind conditions and operator skill as well as by subsequent water management practices in the production area.

A very large proportion of the measured cores in this study were sub-target depth. Since participating growers indicated that they periodically verified their target amounts during the application process, some settling must have occurred after the sand was applied to the production surface. Exposure to rainfall and the weight of winter flood in the weeks prior to the sampling procedure used in this study may have contributed to compaction of the sand layer. Although accuracy (actual : target ratios) may have improved if sampling occurred closer to the time of sand application, logistics (i.e., the winter flood could not be removed without jeopardizing vine health) prevented use of a shorter time frame.

To achieve seedling suppression, the depth of the sand layer at the time of dodder seedling emergence must be at least $25 \mathrm{~mm}$ (Sandler et al., 1997). The samples in this study were taken during the time period that closely coincides with seedling emergence (H.A. Sandler, unpublished data). Thus, although growers were targeting $25 \mathrm{~mm}$ of sand, they still would not have applied enough sand (due to settling, compaction, other factors, etc.) to adequately suppress seedling emergence.

Since the lack of sanding uniformity was so consistent in the 24 farms evaluated in the present study and since dodder infestations are patchy, we suggest that it is unlikely that significant dodder suppression would be achieved unless growers attempted applications of very deep layers of sand (and risk substantial yield reductions). The impact of nonuniform deposition of sand on cranberry girdler and fruit rot has not been fully investigated; however, research on the influence of sanding depth on cranberry fruitworm $(A c$ robasis vaccinii) is being pursued ( $M$. Sylvia, personal communication).

To achieve the greatest horticultural and pest management benefits in the short term, it is imperative to maximize the efficiency of currently available techniques. For the longterm, further discussions between extension personnel and growers are needed to clearly define the obstacles to obtaining uniform sand deposition and accurate target depths. For sand application to be a viable component for integrated management of dodder, alternative methods that improve uniformity of sand deposition must be identified and developed.

\section{Literature cited}

Bewick, T.A., L.K. Binning, and M.N. Dana. 1989. Control of swamp dodder in cranberry. HortScience 24:850

Cross, C.E. and I.E. Demoranville. 1978. Resanding of Massachusetts cranberry bogs. Cranberries 45(2):9-11.

Davenport, J.R. and D.E. Schiffhauer. 2000. Cultivar influences cranberry response to surface sanding. HortScience 35:53-54.

DeMoranville, C.J. 1997. Cultural practices in cranberry production: sanding and pruning, $\mathrm{p}$. 6-10. In: H.A. Sandler (ed.). Cranberry production: A guide for Massachusetts. UMass Amherst Cranberry Sta., East Wareham.

DeMoranville, C.J., H.A. Sandler, and T. Bicki. 1996. Sanding. Best management practices guide for Massachusetts cranberry production. 24 Jan. 2006. <http://www.umass. $\mathrm{edu} /$ cranberry/services/bmp $>$.

Devlin, R.M. and K.H. Deubert. 1980. Control of swamp dodder (Cuscuta gronovii) on cranberry bogs with butralin. Proc. Northeastern Weed Sci. Soc. 34:399-405.

Hunsberger, L.K., W.R. Autio, C.J. DeMoranville, and H.A. Sandler. 2006. Mechanical removal of summer dodder infestations and impacts on cranberry yield. Hort Technology $16: 78-62$

Morrison, J.R., H.A. Sandler, and L.K. Romaneo. 2005. Management of swamp dodder (Cuscuta gronovii Willd.) in cranberry may be enhanced by the integration of a nontoxic household cleaner. Crop Prot. 24:1-6.

Sandler, H.A. 2005. Weed management, p. 18-32. In: M.M. Sylvia and D. Cannon (eds.). Cranberry chart book-Management guide for Massachusetts. UMass Amherst Cranberry Sta., East Wareham.

Sandler, H.A., M.J. Else, and M. Sutherland. 1997. Application of sand for inhibition of swamp dodder (Cuscuta gronovii) seedling emergence and survival on cranberry ( Vaccinium macrocarpon) bogs. Weed Technol. 11:318-323.

Strik, B.C. and A.P. Poole. 1995. Does sand application to soil surface benefit cranberry production? HortScience 30:47-49.

Tomlinson, B. 1937. Proper sanding of great importance in good bog management. Cranberries $1(9): 4,8-11$. 